\title{
Contribuições ao Debate Sobre a RElaçÃo ENTRE GÊNEROS TEXTUAIS E SUPORTE
}

\section{Contributions to the debate about the relation between genres and medium}

\author{
Iara Bemquerer Costa*
}

\section{Ponto de Partida}

\author{
Quando o carteiro chegou \\ E o meu nome gritou \\ Com uma carta na mão \\ Ante surpresa tão rude \\ Nem sei como pude chegar ao portão \\ Lendo o envelope bonito \\ No seu sobrescrito \\ Eu reconheci \\ A mesma caligrafia \\ Que me disse um dia \\ "Estou farto de ti" \\ Porém não tive coragem \\ De abrir a mensagem \\ Porque na incerteza \\ Eu meditava e dizia: \\ "Será de alegria \\ ou será de tristeza" \\ Quanta verdade tristonha \\ Ou mentira risonha \\ Uma carta nos traz \\ E assim pensando, rasguei \\ Tua carta e queimeiPara não sofrer mais ${ }^{1}$
}

Uma questão intrigante no estudo dos gêneros textuais é sua relação com os suportes nos quais os textos escritos são fixados, como condição para sua circulação social. É fácil encontrar casos, como a canção

* UFPR.

${ }^{1}$ Letra da canção "Mensagem", de Cícero Nunes e Aldo Cabral. 
popular transcrita acima, em que gênero e suporte são tratados como indissociáveis. Os autores referem-se a uma carta e fica implícito que a "mensagem" dentro do envelope pertence a esse gênero: tem uma função sociointerativa claramente identificável, associada à carta, e apresenta certamente as características composicionais peculiares a esse gênero. Mas a mesma expressão usada no senso comum para designar o gênero serve também para designar seu suporte, no caso o conjunto composto pelo envelope e folhas de papel. Na canção, há, por um lado, a escolha de expressões diferenciadas para referência ao gênero ("porém não tive coragem / de abrir a mensagem) e ao suporte ("lendo o envelope bonito"). Mas há, por outro lado, o uso da mesma expressão tanto para o suporte, o objeto físico ("com uma carta na mão", "rasguei / tua carta e queimei") quanto para o gênero textual, as propriedades do texto inscrito nesse suporte ("quanta verdade tristonha / ou mentira risonha / uma carta nos traz"). A complexa relação entre gêneros textuais e suportes é um tema ainda pouco explorado, cujo estudo pode contribuir para a compreensão dos processos de emergência, transmutação e circulação dos gêneros.

Para discutir esse tema, vamos tomar como ponto de partida um texto de Luiz Antônio Marcuschi - "A questão do suporte dos gêneros textuais" - que podemos caracterizar como um trabalho duplamente provisório: 0 texto circulou em uma versão preliminar (de 18/05/2003) e não foi revisto nem publicado; além disso, o próprio autor nos alerta para o caráter não conclusivo de suas observações, que ele apresenta como um convite à discussão. Neste trabalho pretendemos atender ao convite formulado no ensaio, com a preocupação de deslocar e reformular algumas de suas propostas.

Marcuschi (2003b) propõe inicialmente uma tese central: "todo gênero tem um suporte". Na sequência, apresenta o conjunto de categorias analíticas de que se servirá para o estudo proposto: texto, discurso, domínio discursivo ou esfera de atuação humana, gênero textual/discursivo, tipo de texto/de discurso, evento discursivo, serviço, canal, instituição e grandes continentes (bibliotecas e livrarias). A seguir expõe a noção de suporte e discute sua influência sobre o gênero. Faz uma apresentação não exaustiva dos suportes convencionais (livro, livro didático, jornal diário, revista semanal/mensal, revista científica, boletins e anais, rádio, televisão, telefone, quadro de avisos, outdoor, encarte, fôlder, luminosos, faixas) e também dos suportes incidentais (embalagem, parachoques e paralama de caminhão, roupas, corpo humano, paredes, muros, paradas de ônibus, estações de metrô, calçadas, fachadas, janelas de ônibus e outros meios de transporte). Destaca ainda a distinção entre suporte e serviços (correios, programa de $e$ mail, mala direta, Internet, homepage e site). Finalmente aponta a relação entre o suporte textual e as formas de leitura. Nas seções seguintes, vamos retomar algumas de suas proposições para discuti-las, propor reformulações e deslocamento de foco. 


\section{A Natureza do GÊnero TeXtual e Do Suporte}

Queremos destacar inicialmente a tese central do texto e alguns corolários a ela relacionados. Marcuschi afirma no primeiro parágrafo do seu ensaio: "a tese central é a de que todo gênero tem um suporte, mas a distinção entre ambos nem sempre é simples e a identificação do suporte exige cuidado". Afirma também que o suporte é "imprescindível para que o gênero circule na sociedade e deve ter alguma influência na natureza do gênero suportado" (MARCUSCHI, 2003b, p. 1). Segundo ele, há entre o gênero e o suporte uma relação de indexação ou de coemergência, ou seja, as materializações de um gênero estariam sempre acopladas ao mesmo tipo de suporte. Para discutir suas propostas, é necessário, inicialmente, esclarecer os conceitos de gênero e suporte que o autor adota.

Vejamos inicialmente o conceito de suporte, que aceitamos sem restrições:

Intuitivamente, entendemos aqui como suporte de um gênero um lócus físico ou virtual com formato específico que serve de base ou ambiente de fixação do gênero materializado como texto. Numa definição sumária, pode-se dizer que suporte de um gênero é uma superfície física em formato específico que suporta, fixa e mostra um texto (MARCUSCHI, 2003, p. 5, grifos do autor).

Já a formulação do conceito de gênero não é tão clara. No glossário das categorias analíticas relevantes para seu estudo, Marcuschi (2003b, p. 3 , grifos do autor) define:

Gênero (textual, de texto, discursivo, do discurso) - Trata-se de textos orais ou escritos materializados em situações comunicativas recorrentes. Os gêneros textuais são os textos que encontramos em nossa vida diária com padróes sócio-comunicativos característicos definidos por sua composição, objetivos enunciativos e estilo concretamente realizados por forças históricas, sociais, institucionais e tecnológicas. Os gêneros constituem uma listagem aberta, são entidades empíricas em situações comunicativas e se expressam em designações tais como: sermão, carta comercial, [...].

O conceito de gênero textual/discursivo apresentado nesses termos sugere que haja uma equivalência entre gênero e texto. Esta mesma equivalência é indicada também em Marcuschi (2003a p. 23, grifos do autor):

Usamos a expressão gênero textual como uma noção propositalmente vaga para referir os textos materializados que 
encontramos em nossa vida diária e que apresentam características sócio-comunicativas definidas por conteúdos, propriedades funcionais, estilo e composição característica.

A apresentação do conceito de gêneros textuais nos dois trabalhos citados dá a entender que Marcuschi considera gêneros e textos materializados como equivalentes.

Mas podemos observar também que nas duas passagens citadas, o autor apresenta longas listas de gêneros. Estas revelam que, apesar da forma imprecisa com que os gêneros são definidos, o autor quer se referir a critérios de agrupamento de textos. Para conferir essa leitura, recorremos à definição de texto que Marcuschi (2003b, p. 2) também inclui no seu glossário das categorias de análise. Ao conceituar texto, o autor destaca sua dupla natureza de processo e produto, associada ao evento comunicativo e ao caráter de objeto linguístico. Há um trecho do trabalho em que ele procura relacionar texto e gênero em um diagrama que contém todo o conjunto de categorias analíticas utilizado. Ao fazê-lo o autor liga os dois conceitos por um sinal bidirecional ( $<->$ ), que podemos entender como uma referência ao processo de materialização dos gêneros em textos mencionado no conceito de suporte.

A posição do autor frente a essa questão fica mais clara em um trabalho posterior (MARCUSCHI, 2006 [2005]), em que se percebe a preocupação em distinguir os dois conceitos. É essa distinção que lhe permite afirmar, por exemplo, que "todo gênero se realiza em textos" (idem, p. 25). Ou ainda:

Em suma, os gêneros não são superestruturas canônicas e deterministas, mas também não são amorfos e simplesmente determinados por pressões externas. São formações interativas, multimodalizadas e flexíveis de organização social e de produção de sentidos (MARCUSCHI, 2006 [2005], p. 25).

É importante destacar que a nossa discussão sobre o papel dos suportes dos gêneros tem como ponto de partida a diferença entre gêneros e textos empíricos, materializados, sem a qual o conceito de gênero textual/ discursivo não se sustenta. Entendemos gênero como um princípio de agrupamento de textos associados a eventos interativos similares e que apresentam características recorrentes na sua organização e estilo. Essa posição está presente de formas diferenciadas em dezenas de autores que tratam da questão. Vamos aqui retomar o conceito em cinco autores, representativos de duas abordagens diferenciadas do estudo dos gêneros, segundo classificação de Meurer, Bonini e Motta-Roth (2005). Consideremos inicialmente dois autores que se filiam a abordagens sociorretóricas: Swales e Bazerman.

A ideia de gêneros como princípio de agrupamento de textos está presente no estudo já clássico de Swales (1990, p. 58): 
Um gênero compreende uma classe de eventos comunicativos, cujos exemplares compartilham os mesmos propósitos comunicativos. Esses propósitos são reconhecidos pelos membros mais experientes da comunidade discursiva original e constituem a razão do gênero. A razão subjacente dá o contorno da estrutura esquemática do discurso e influencia e restringe as escolhas de conteúdo e estilo. o propósito comunicativo é o critério que é privilegiado e que faz com que o escopo do gênero se mantenha enfocado estreitamente em determinada ação retórica compatível com o gênero. Além do propósito, os exemplares do gênero demonstram padrões semelhantes, mas com variações em termos de estrutura, estilo, conteúdo e público-alvo².

Nesta definição percebe-se claramente a distinção entre o gênero, definido como uma classe de eventos comunicativos que compartilham os mesmos propósitos e os textos empíricos em que o gênero se materializa, apresentados pelo autor como os exemplares do gênero. Para Swales, os gêneros são um princípio de classificação, que tem como objeto os eventos comunicativos. Os textos empíricos compartilham características com os demais exemplares, embora cada um apresente também características peculiares.

Bazerman destaca o caráter de ação social dos gêneros, mas, de forma alguma, indica sua identificação com textos efetivamente produzidos. Segundo ele,

os gêneros constituem um recurso rico e multidimensional que nos ajuda a localizar nossa ação discursiva em relação a situações altamente estruturadas. O gênero é apenas a realização visível de um complexo de dinâmicas sociais e psicológicas. Ao compreendermos o que acontece com o gênero, porque o gênero é o que é, percebemos os múltiplos fatores sociais e psicológicos com os quais nossos enunciados precisam dialogar para serem mais eficazes (BAZERMAN, 2006 [1997], p. 29).

Para Bazerman, os gêneros resultam da tipificação, manifestada nos textos, de dinâmicas sociopsicológicas. As propriedades recorrentes nos exemplares de cada gênero só podem ser identificadas a partir da observação de um conjunto de textos materializados (enunciados) reconhecidos como realizações de um gênero.

A concepção de gêneros como princípio de agrupamento de textos está presente também em autores classificados por Meurer, Bonini e MottaRoth (2005) como filiados a uma abordagem sociodiscursiva. É o caso dos estudiosos ligados ao Grupo de Genebra, representados aqui por Bronckart, Schneuwly \& Dolz.

${ }^{2}$ Citamos aqui a tradução de Hermais \& Biasi-Rodrigues (apud MEURER; BONINI; MOTTAROTH; 2005, p. 114). 
A questão dos gêneros tem uma importância secundária no trabalho de Bronckart. Mesmo assim, ele propõe uma série de cuidados para garantir a objetividade na coleta de textos estudados, para obter um corpus representativo dos gêneros orais e escritos em circulação em um determinado contexto social: no caso, os países europeus de língua francesa. Também para ele, o gênero de texto é um princípio que permite o agrupamento de textos efetivamente produzidos.

Chamamos de texto toda unidade de produção de linguagem situada, acabada e auto-suficiente (do ponto de vista da ação ou da comunicação). Na medida em que todo texto se inscreve, necessariamente, em um conjunto de textos ou em um gênero, adotamos a expressão gênero de texto em vez de gênero do discurso (BRONCKART, 2003 [1997], p. 75, grifos do autor).

O autor faz claramente a distinção entre os textos materializados - sempre únicos, produzidos em situações concretas - e um princípio de agrupamento, ou seja, os conjuntos em que esses textos se inscrevem. Para Bronckart (2003 [1997], p. 100), os gêneros se organizam como uma nebulosa, com alguns conjuntos delimitados claramente e rotulados pelos usuários e outros conjuntos vagos, que apresentam classificações instáveis ou divergentes.

Schneuwly e Dolz (2004) assumem uma conceituação de gêneros textuais bastante marcada pelas contribuições de Bakhtin e Vygotsky, e apresentam como característica principal dos gêneros seu caráter de instrumentos semióticos. Esses autores procuram refletir sobre os gêneros textuais como objetos de ensino. Isso faz com que enfatizem sua estabilidade, seu caráter modelar, a recorrência de um conjunto de características estruturais. Para eles, é essa estabilidade que permite a elaboração de sequências didáticas centradas na exploração de conjuntos de gêneros:

Para definir um gênero como suporte de uma atividade de linguagem três dimensões parecem essenciais: 1) os conteúdos e os conhecimentos que se tornam dizíveis por meio dele; 2) os elementos das estruturas comunicativas e semióticas partilhadas pelos textos reconhecidos como pertencentes ao gênero; 3) as configurações específicas de unidades de linguagem, traços, principalmente, da posição enunciativa do enunciador e dos conjuntos particulares de seqüências textuais e de tipos discursivos que formam sua estrutura. O gênero, assim definido, atravessa a heterogeneidade das práticas de linguagem e faz emergir toda uma série de regularidades no uso. São as dimensões partilhadas pelos textos pertencentes ao gênero que lhe conferem uma estabilidade de fato, o que não exclui evoluções, por vezes, importantes (SCHNEUWLY; DOLZ 2004, p. 75).

Schneuwly e Dolz definem conjuntos de gêneros levando em conta, 
além dos domínios sociais de comunicação, os aspectos tipológicos (tipos de sequências recorrentes) e as capacidades de linguagem dominantes, característica relevante para o planejamento de atividades de leitura e produção de textos na escola, tendo os gêneros como categoria central.

Estabelecidos os conceitos nucleares para iniciar a discussão do tema, voltemos à tese formulada por Marcuschi (2003b, p. 1) para indagar: a afirmação de que "todo gênero textual tem um suporte" é aceitável? Antes de procurar responder essa questão, é relevante observar que Marcuschi (2003b, p. 5) não faz essa generalização apenas sobre os gêneros, mas também em relação aos textos, ao afirmar que "todos os textos ancoram em algum suporte".

\section{Sobre a RelaçÃo Entre GÊneros e Suportes}

As observações acima nos levam, inicialmente, a desdobrar a tese de Marcuschi em duas proposições:

(a) Todo texto tem um suporte.

(b) Todo gênero textual tem um suporte.

Tomemos inicialmente a proposição (a), de caráter mais particular. Essa afirmação está ancorada em uma concepção grafocêntrica, segundo a qual a fixação em um suporte é condição para a circulação dos textos. Desde que os estudos dos gêneros textuais/discursivos incorporaram as formulações de Bakhtin (1992 [1952-3]), os estudiosos procuram abordar tanto os gêneros orais quanto escritos a partir de um mesmo conjunto de categorias analíticas. O suporte é com certeza uma categoria pertinente para o estudo dos textos escritos e multimodais ${ }^{3}$, para os quais a afirmação (a) é claramente verdadeira, mas não é uma categoria que se aplique aos textos orais.

Ao contrário da afirmação de Marcuschi de que o suporte "é imprescindível para que o gênero circule na sociedade" (MARCUSCHI, 2003b, p. 1), preferimos restringir essa afirmação aos gêneros escritos e multimodais. As tentativas que Marcuschi faz de encontrar o suporte dos gêneros orais resultam em mais problemas do que esclarecimentos. $O$ autor tenta atribuir suportes aos gêneros orais, pois para ele: "Seguramente, a ninguém ocorre

\footnotetext{
${ }^{3}$ Dionísio (2006, p. 133) apresenta a multimodalidade como um traço constitutivo dos textos falados e escritos. Segundo ela, "Se as ações sociais são fenômenos multimodais, conseqüentemente, os gêneros textuais falados e escritos são também multimodais porque, quando falamos ou escrevemos um texto, estamos usando no mínimo dois modos de apresentação: palavras e gestos, palavras e entonações, palavras e imagens, palavras e tipográficas, palavras e sorrisos, palavras e animações etc.". Ao nos referirmos aqui a "textos escritos (ou multimodais)", estamos fazendo um uso mais restrito da expressão. Nossa intenção é incluir na generalização feita sobre os textos escritos aqueles que são materializados em mais de uma forma: palavras e figuras, ou fotos, gráficos, cores, infográficos, tamanho e formato das letras etc.
} 
que a boca seja um suporte, mas algum tipo de suporte para os gêneros orais deve haver, já que eles não estão soltos" (MARCUSCHI, 2003b, p. 2). Vejamos algumas consequências dessa posição.

Um primeiro problema diz respeito à superposição de categorias analíticas. Por exemplo, em alguns casos, Marcuschi propõe a identificação entre suporte e evento: "Talvez, no caso da oralidade, sejam os próprios eventos os suportes, por exemplo, um congresso acadêmico seria o suporte de conferências e comunicações orais e a mesa-redonda seria o suporte de exposições temáticas" (MARCUSCHI, 2003b, p. 2, grifos do autor).

Ora, o conceito de evento é fundamental para a análise de qualquer gênero. Nas abordagens sociorretóricas, é o critério nuclear para o reconhecimento dos gêneros. Não custa lembrar a definição de Swales (1990, p. 58), para quem o gênero é uma "classe de eventos comunicativos". O acavalamento entre as categorias suporte e evento não contribui para o esclarecimento do papel de um ou outro na produção e circulação dos gêneros orais.

Em outro ponto do seu ensaio, Marcuschi propõe que a instituição seja o suporte para alguns gêneros orais, havendo também nesse caso a superposição de duas categorias analíticas relevantes: "Assim, pode-se dizer que em certos casos a instituição serviria de suporte, como por exemplo, a escola seria um suporte para as aulas expositivas" (MARCUSCHI, 2003b, p. 2 , grifos do autor). Aqui também a equivalência entre suporte e instituição cria dificuldades para o uso do conceito de instituição, relevante para o estudo dos chamados gêneros secundários nas análises mais diretamente vinculadas aos fundamentos bakhtinianos.

Na página 12 de seu ensaio, Marcuschi (2003) apresenta como suportes dos gêneros orais o rádio, a televisão e o telefone, em uma análise inconsistente com o conceito de suporte apresentado no mesmo trabalho: "Suporte textual tem a ver centralmente com a idéia de um portador do texto, mas não no sentido de um meio de transporte ou veículo..." (MARCUSCHI, 2003b, p. 4, grifos do autor). Rádio, televisão e telefone seriam exatamente canais, ou meios de transporte ou veículos dos gêneros orais.

Para evitar as inconsistências decorrentes da tentativa de encontrar os suportes dos textos orais, a proposição (a) deve ser reformulada para:

(a') Todo texto escrito (ou multimodal) tem um suporte.

Voltemos agora à proposição (b), que se refere a dois princípios de classificação/agrupamento numa relação de co-ocorrência: agrupamento de textos empíricos (gêneros) e de lócus materiais ou virtuais (suportes). Se os gêneros forem entendidos como princípios de agrupamento de textos empíricos e de realização de dinâmicas sociais, retóricas, discursivas e psicológicas, a afirmação de Marcuschi (2003b, p. 1) segundo a qual "todo gênero tem um suporte" só poderia ser aceita na medida em que os mesmos fatores que levam a selecionar um gênero atuassem simultaneamente na seleção de um 
suporte prototípico ao qual o gênero seria associado para materializar-se como texto.

Neste caso, é fácil observar que nem todos os gêneros podem ser associados a suportes prototípicos. Tomemos a relação gênero/suporte num gênero bem consolidado como a receita culinária: uma receita pode ter suportes extremamente variados, e manter tanto sua relação com os eventos interativos em que é tipicamente produzida/interpretada quanto as características formais estabilizadas. Encontramos receitas culinárias em cadernos, livros, revistas, embalagens de produtos, sites da Internet, programas de televisão, instruções orais etc. O gênero convite, para ilustrar nosso ponto de vista com outro exemplo, pode ser divulgado em cartão, em e-mail, cartaz, mala-direta, telefonema etc. Um romance pode ser apresentado em seu suporte tradicional, impresso ou em suporte digital, em CD-ROM ou página da WEB. A tradicional carta, fechada em um envelope para garantir o sigilo do texto para o interlocutor único, quando transformada em carta do leitor passa a ter o jornal ou revista como suporte; se for uma carta aberta a determinado grupo de interlocutores, pode ser impressa em panfletos ou fixada em cartazes.

Em síntese, Marcuschi direcionou sua análise para a busca de uma relação de co-ocorrência que o levou a procurar o suporte de cada gênero, a partir de sua tese nuclear de que todo gênero tem um suporte. Acreditamos haver demonstrado que essa tese não se sustenta: há uma variedade imensa de gêneros orais, para os quais a categoria de suporte não se aplica e há também gêneros que podem ser inscritos em diferentes suportes.

Essas observações não reduzem o interesse no estudo da relação entre os gêneros textuais e os suportes. Esse estudo pode ser redirecionado para o exame de outras hipóteses, não aventadas por Marcuschi. Vamos a seguir apontar algumas direções para o estudo da relação entre gêneros e suportes.

\section{PARa Concluir: Algumas Hipóteses a Serem Exploradas}

Assumimos acima que todo texto escrito (ou multimodal) tem um suporte, condição para sua circulação. Na maioria dos casos, pode-se afirmar também que os gêneros textuais têm um suporte prototípico. Os estudiosos do tema têm como ponto de partida a identificação dos gêneros feita por seus usuários, a percepção que eles têm dos gêneros de que se utilizam nas diversas esferas de atuação. No processo de reconhecimento dos gêneros textuais que usam no seu cotidiano, os falantes estabelecem uma relação metonímica entre os gêneros textuais e os suportes que permitem sua circulação, devido à própria natureza do suporte, à sua concretude. Ou seja, a denominação social de uma enorme variedade de gêneros não se diferencia dos seus suportes prototípicos: carta, outdoor, banner, panfleto, fôlder, faixa, capa (de livro ou revista), orelha, encarte, bula, letreiro etc. 
Isso nos leva a apontar o papel do suporte no surgimento ou transformação dos gêneros como uma questão interessante a ser aprofundada em estudos futuros. A criação de novos suportes resulta no surgimento de novos gêneros, numa interligação tão estreita que os usuários usam a mesma expressão tanto para o gênero quanto para o suporte. Bazerman (2005) mostra como as mudanças nas ações associadas às cartas produziram ao longo da história sucessivos desdobramentos nesse gênero. As transmutações de um gênero em outros podem ser também o resultado da disponibilidade de novos suportes. É o que se observa, por exemplo, com o surgimento do e-mail, a partir da criação do suporte digital acoplado ao serviço da Internet. $\mathrm{O} e$ mail surge como uma transformação da carta pessoal e comercial. O mesmo suporte e serviço permitem o surgimento da news letter, como transformação da mala direta postal e dos boletins eletrônicos das grandes empresas, gênero que surge a partir dos jornais institucionais.

Outra questão interessante a ser investigada são as condições que levam os usuários a reconhecer a distinção entre gêneros e suportes. Isso acontece, com certeza, naqueles casos em que não se observa uma relação biunívoca. Enquanto o outdoor, por exemplo, é suporte prototípico de um só gênero (o texto publicitário), há casos de suportes associados a uma multiplicidade de gêneros. $O$ jornal apresenta editoriais, crônicas, cartas de leitor, notícias, reportagens, resenhas, horóscopos, textos de opinião, críticas de arte, charges, tirinhas, notas sociais, anúncios classificados, textos publicitários etc. Esta multiplicidade torna mais fácil aos usuários reconhecerem os gêneros e distingui-los dos suportes. O livro (suporte) pode comportar gêneros muito diversos: romances, contos, poesias, manuais, dicionários, enciclopédias, biografias, autoajuda, ensaios etc. A relação biunívoca entre o gênero e o suporte pode ser quebrada também quando um gênero passa a ser fixado em diferentes suportes, como a receita culinária e o convite. Uma questão interessante a ser investigada na relação entre gêneros e suportes é como e porque a relação biunívoca entre ambos é desfeita.

Não se pode negar também que o suporte afeta a leitura, questão apontada por Marcuschi (2003b): o mesmo texto publicitário fixado num outdoor ou inserido em uma revista semanal será lido de formas diferentes conforme seu suporte: a leitura do outdoor é feita à distância e muitas vezes rapidamente, de dentro de um veículo em movimento, enquanto na revista o leitor pode manusear o texto, observar detalhes, fazer a leitura em ritmos diferenciados e em ambientes que permitam maior concentração. Da mesma forma, há diferenças significativas na leitura de um jornal impresso ou em suporte digital. Podemos assistir a uma ópera com o texto publicado em libreto, mas é comum também atualmente o texto ser projetado em multimídia em espaço acima ou ao lado do palco. O gênero e o texto são os mesmos, mas a relação com o leitor é diferente em um ou outro caso. $O$ libreto pode ser lido antes ou depois da encenação, já a leitura do texto projetado se dá simultaneamente com a apresentação dos cantores e orquestra, de modo que a ligação entre ambas se faz cena a cena. Nesses 
casos, a relação do leitor com o suporte interfere na sua relação com o texto.

Não é por acaso que as agências de publicidade frequentemente veiculam uma mesma campanha publicitária em vários suportes como uma forma de sensibilizar os interlocutores de formas diferenciadas. Essa estratégia provém do reconhecimento de que o suporte é relevante na interação do leitor com o texto.

Outra questão interessante na relação entre os gêneros textuais e os suportes é o efeito que se observa quando um texto é fixado em um suporte diferente daquele que é prototípico para o gênero. Nesse caso, o suporte não só permite a circulação do texto como contribui para a construção do seu sentido. Observe-se o exemplo abaixo, no qual o catálogo de uma exposição de pintura tem como suporte uma embalagem que lembra uma caixa de chá e os quadros expostos são reproduzidos em pequenas cartelas presas em barbante semelhantes a saquinhos de chá. Esse suporte para o catálogo contribui para a interpretação do texto de apresentação da exposição, que tem como título "Chá com Alice". O catálogo apresentado nesse suporte lembra ao visitante que ele é convidado a tomar um chá com a personagem de Lewis Carroll, o que interfere na forma como vai interagir com os quadros expostos nas paredes do museu.

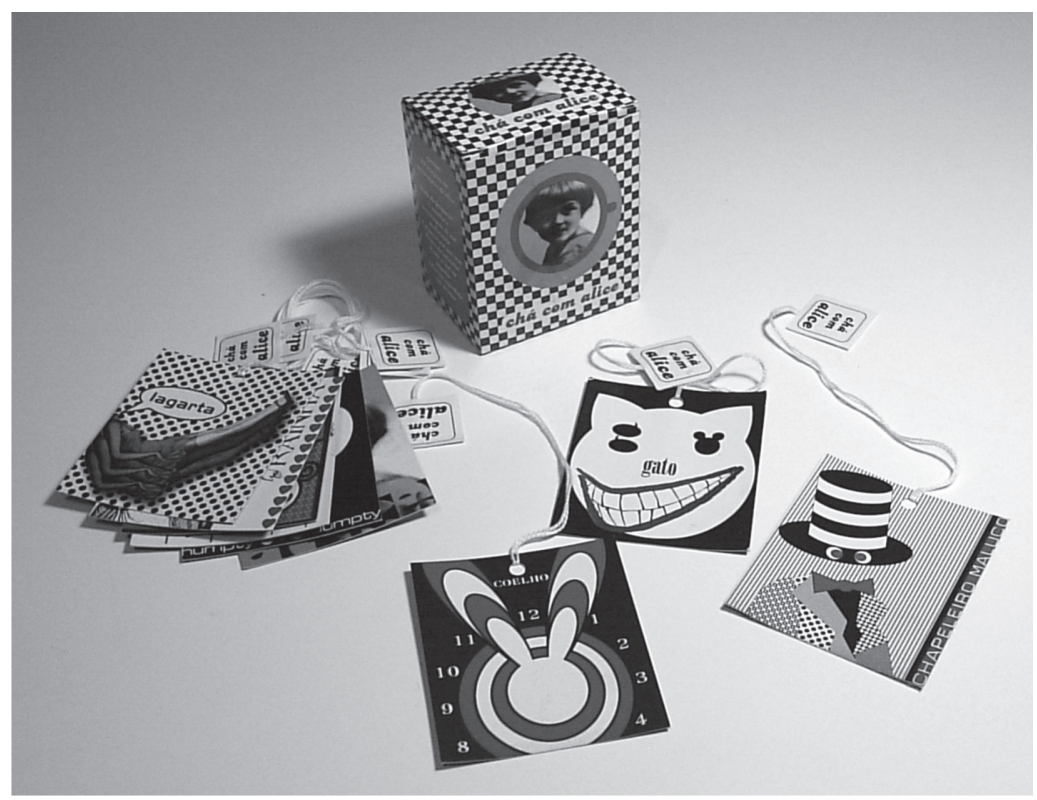

Neste caso, além do suporte, observa-se a exploração da intergenericidade (ver MARCUSCHI, 2005) para a construção do efeito de sentido. Nas laterais da caixinha, há indicações sobre seu conteúdo e modo de usar, que por um lado dão informações sobre a exposição - como um catálogo - e por outro lado usam elementos de uma embalagem. Há 
informações sobre o autor, o produtor, os patrocinadores e a concepção da exposição com o uso de elementos próprios de uma embalagem: ingredientes, conservação, prazo de validade, conteúdo, modo de preparar.

\begin{tabular}{|c|c|}
\hline ingredientes: & contém: \\
imaginação misturada & og imagens de \\
com brincadeira de & personagens de Alice \\
concepção e design & \\
gráfico de & modo de preparar: \\
Adriana Alegria e & 1.escolhao \\
produção de & personagem de sua \\
Marco Bucelli & preferência \\
conservar em: & 2.pegueo ímá que vem \\
ambiente fantásticoe & dentro da caixinha \\
agradável & 3.cole o imã no \\
& pegador \\
prazo de validade: & 4.fixe na superficie \\
infinito & que desejar \\
& \\
\hline
\end{tabular}

Pode-se postular que a circulação de um texto em suporte não convencional para o gênero resulta sempre em um efeito de sentido também diferente. Se alguém usa um outdoor para fazer circular o texto "Maria, eu te amo", produzirá um efeito muito diverso do ocorreria se fizesse a mesma declaração oralmente, tendo a interessada como única interlocutora, ou usando algum suporte convencional como o cartão ou bilhete. O outdoor desloca a relação com o interlocutor, fazendo com que o mesmo texto passe a ser interpretado como uma forma de tornar público o sentimento. Nesse suporte, o texto passaria a ser lido como: "Saibam todos que por aqui passarem que eu (quem?) amo Maria (qual Maria?)".

Apontamos, assim, algumas direções para o estudo da relação entre os gêneros textuais e os suportes. Indicamos inicialmente situações em que os gêneros e seus suportes são percebidos pelos usuários como indissociáveis, o que faz com que os nomes com que os gêneros são designados pelos usuários sejam iguais aos seus suportes prototípicos, como se vê na referência à carta na canção popular citada no início deste artigo. Levantamos também a hipótese de que a criação de novos suportes (que podem ser associados a serviços) seja um fator altamente relevante para o surgimento de novos gêneros e a transformação de gêneros consolidados. Outra questão interessante na relação entre os gêneros e os suportes é a indicação de que os suportes afetam a interpretação dos textos: há gêneros que podem circular em suportes diferenciados, mas a escolha de um ou outro suporte interfere na relação com o interlocutor. Mostramos, finalmente, que a escolha de suportes não prototípicos para a circulação do gênero em que o texto se enquadra contribui para a construção de efeitos de sentido diferentes.

As quatro formas de focalizar a relação entre os gêneros textuais 
e os suportes que destacamos mostram o interesse em aprofundar o estudo desta questão. Para fazê-lo, é necessário, contudo, focalizá-la a partir de pontos de vista muito diferentes daquele proposto por Marcuschi (2003b). Em vez de testar a relação biunívoca um gênero/um suporte percorrendo a lista de gêneros em circulação em um dado contexto social e a lista dos suportes convencionais, há uma série de questões interessantes que envolvem a forma como gênero e suporte se unem ou se distanciam, como cada um interfere no surgimento, estabilização, circulação social e modificação do outro.

Para finalizar, citamos o historiador Roger Chartier, especialista em história do livro:

Temo, entre outras coisas, que os livros eletrônicos possam transformar bibliotecas inteiras em algo obsoleto. É preciso questionar a idéia de que um livro é sempre o mesmo livro qualquer que seja a sua forma. Isso não é verdade. Todo o trabalho que fazemos como historiadores do livro é mostrar que o sentido de um texto depende também da forma material como ele se apresentou aos seus leitores originais e ao seu autor. Por meio dela podemos compreender como e por que foi editado, a maneira como foi manuseado, lido e interpretado por aqueles do seu tempo. Não há equivalência entre os suportes materiais. [...] Existem perguntas que não podem ser feitas apenas a um texto, têm de ser feitas em conjunto com seu suporte (Entrevista à Folha de S. Paulo, 8 jan. 2006).

\title{
RESUMO
}

Marcuschi (2003b) afirma que "todo gênero tem um suporte" e analisa a relação entre diferentes gêneros textuais e seus suportes. Questionamos neste trabalho a validade de sua tese, a partir de evidências relacionadas a gêneros orais e escritos. Discutimos também o papel dos suportes no surgimento, transformação e circulação dos gêneros.

Palavras-chave: gêneros textuais; suporte; circulação.

\begin{abstract}
Marcuschi (2003b) claims that "every genre has its medium" and analyses the relationship between various textual genres and their respective media. This essay questions the validity of his thesis, through evidence from oral and written genres. The role of the media in the birth, transformation and circulation of the genres is also discussed.

Keywords: textual genre; media; circulation.
\end{abstract}




\section{REFERÊNCIAS}

BAKHTIN, Mikhail Os gêneros do discurso. In: . Estética da criação verbal. São Paulo: Martins Fontes, 1992. p. 279-326.

BRONCKART, Jean-Paul. Atividades de linguagem, textos e discursos. 2. ed. São Paulo: EDUC, 2003.

BAZERMAN, Charles. Gênero, agência e escrita. São Paulo: Cortez, 2006.

Gêneros textuais, tipificação e interação. São Paulo: Cortez, 2005.

DIONISIO, Ângela Paiva. Gêneros multimodais e multiletramento. In: KARWOSKI, A. M.; GAYDECZKA, B.; BRITO, K. S. Gêneros textuais: reflexão e ensino. 2. ed. Rio de Janeiro: Ed. Lucerna, 2006. p. 131-144.

MARCUSCHI, Luiz Antônio. Os desafios da identificação do gênero textual nas atividades de ensino: propósitos comunicativos versus forma estrutural. Conferência. III SIGET, Universidade Federal de Santa Maria, 16-18 ago. 2006.

Gêneros textuais: configuração, dinamicidade e circulação. In: KARWOSKI, A. M.; GAYDECZKA, B.; BRITO, K. S. Gêneros textuais: reflexão e ensino. 2. ed. Rio de Janeiro: Ed. Lucerna, 2006. p. 23-36.

Gêneros textuais: definição e funcionalidade. In: DIONÍSIO, A. P.; MACHADO, A. R.; BEZERRA, M. A. (Orgs.). Gêneros textuais e ensino. 2. ed. Rio de Janeiro: Editora Lucerna, $2003 a$.

. A questão do suporte dos gêneros textuais. Mimeo, 2003b.

MEURER, J. L.; BONINI, Adair; MOTTA-ROTH, Désirée (Orgs.). Gêneros: teorias, métodos, debates. São Paulo: Parábola, 2005.

SCHNEUWLY, Bernard; DOLZ, Joaquim et al. Gêneros orais e escritos na escola. Campinas: Mercado de Letras, 2004.

SWALES, John M. Genre analysis: English in academic and research settings. Cambridge: Cambridge University Press, 1990.

Submetido em: 13/06/2008.

Aceito em: 07/07/2009. 